\title{
LÉXICO, DICIONÁRIOS E TRADUÇÃO NO PERÍODO COLONIAL HISPÂNICO
}

\section{Consuelo Alfaro Lagorio}

Uma das marcas que evidenciam o contato, mais especificamente, a dinâmica das sociedades, se encontra no léxico. Nos processos militares de conquista, os elementos da cultura material das sociedades conquistadas que passam a integrar as práticas sociais dos conquistadores, por exemplo, plantas e animais, geralmente são incorporados com os termos que as designam, após um período de ajustes em razão das dificuldades de tradução. Na língua espanhola, termos como canoa, ${ }^{1}$ axi, hamaca, maiz, são incorporadas aos dicionários nos primeiros momentos da Conquista, já no século XVI. Posteriormente, entradas léxicas como tomate, chocolate, batata, llama e tantas outras procedentes de América indígena fazem parte de Dicionários, a partir do século XVIII, institucionalizadas como patrimônio léxico. Nos primeiros documentos de registro ibéricos, contudo, as descriçóes feitas desses elementos e os nomes desses objetos se ancoram nas categorias conhecidas dos cronistas, ${ }^{2}$ e só após estabilizar o empréstimo se consolida esse processo no registro do dicionário.

Essas entradas consignam os itens de materialidade concreta. No entanto, existem outros desdobramentos para os conceitos e as categorias de natureza étnica, como aqueles que se referem à organização social, política ou à cosmogonia das sociedades indígenas, que não têm correspondências com as categorias das línguas europeias. Na nova ordem social e jurídica, muitas dessas categorias são ressemantizadas, isto é, ganham outros significados nas línguas de origem, por força das tensōes institucionais.

\footnotetext{
${ }^{1}$ De origem taino, este termo está registrado no Vocabulario español-latino de Antonio de Nebrija [1495]. Ed. facsimilar de Madrid, Real Academia Española, 195: f.XXIIIv.

${ }^{2}$ No caso das referências ao mundo andino, as primeiras crônicas espanholas se referem às lhamas como carneros, e até uma Crônica escrita em espanhol por um índio se refere da mesma forma. (GUAMÁN POMA, Felipe. Nueva Crónica y buen gobierno.[1616] Historia 16: Madrid, 1987: 270.)
} 


\section{Línguas Indígenas e Catequese}

Dentre as medidas que fazem parte das decisões políticas da administração colonial na América Hispânica, uma diz respeito à tradução. Depois de encerrado o processo de Conquista, organizar e gerenciar a nova ordem social requer disposições legais, entre as quais são fundamentais as que se referem às línguas. Esse processo de intervencionismo e planejamento é acionado pelas duas instâncias de poder. De um lado, a Igreja - o órgão formulador e executor dessa política, a partir da práxis das ordens missionárias e, de outro lado, a instância política -, a Coroa, órgão sancionador através do corpo de medidas legais, que dão força de lei a essas propostas.

Ao longo da Conquista e em todo o período colonial, a administração hispânica se serviu das categorias proporcionadas pelos estudiosos das línguas - missionários e cronistas - que usaram uma classificação funcional: línguas gerais vs. línguas particulares. A Lingua Geral se refere à língua de uma região ou de uma zona multilíngue, que serve como veículo de comunicação interétnica entre falantes de línguas particulares. Uma das primeiras providências dos colonizadores foi identificar aquelas línguas que permitiam um relativo leque comunicativo, avaliando que o seu uso dispensava a aprendizagem e abordagem das línguas minoritárias.

No caso andino, a língua geral que tinha servido para a administração inca era o Quéchua. Após ser avaliada em sua funcionalidade, passa a ser objeto de medidas do que hoje conhecemos como "planejamento linguístico", tais como, escolha da norma e sua implantação, principalmente no processo evangelizador, deixando, neste campo, farta documentação. Nesse sentido, a sua codificação normativa (edição de gramáticas) e ortográfica (com propostas minimizadoras das diferenças dialetais) instrumentalizam a língua para desempenhar novas funções. Certamente naquela em que mais se investiu foi na de criar discursos religiosos, com o intuito de substituir as práticas religiosas andinas.

Como subsídio para analisar os pressupostos da política de línguas, cabe assinalar a tradução como uma das práticas mais marcantes na configuração e formação de um corpus na língua escrita. $\mathrm{Na}$ corte de Toledo, no período alfonsino, ${ }^{3}$ grupos de eruditos, fluentes nos registros cultos nas línguas clássicas, especialmente hebreu e ára-

${ }^{3}$ Refere-se ao período do rei de Castilha e Leon Alfonso X, século XIII, conhecido como Alfonso el sábio, pelas políticas protecionistas em vários campos do saber, notadamente a literária e a história. 
be, formaram uma espécie de colegiado, para traduzir ao castelhano a produção literária dessas línguas. A tarefa de traduzir passava por deliberaçôes sobre "fidelidade" e qualidades textuais das versões ao castelhano, que configuram uma importante tradição.

Os Concílios Provinciais assumem a responsabilidade de produzir uma traducción auténtica del Catecismo y Doctrina Cristiana para ser difundida, função que será delegada a personas doctas y hábiles en lengua que hiciesen la dicha traducción. * Este é o modelo de política linguística trazido na bagagem do clero letrado - uma minoria nas hostes conquistadoras. O modelo será implementado nas propostas políticas das bases americanas, norteado pelas diretrizes metropolitanas.

Desta forma, planejar a catequese, eixo no ordenamento social que constitui uma prática importante, requer tomar decisões no campo das línguas. Em função de sua natureza, uma das primeiras deliberaçôes institucionais, através dos Concílios, é instaurar uma linha pastoral para ordenar as práticas de catequese, que já vinham se desenvolvendo durante cinquenta anos ao longo da ocupação, tentando estabelecer linhas claras de atuação.

A tarefa da tradução do material catequético para a língua geral indígena segue os moldes toledanos, acrescidos dos cuidados inquisitoriais no que a Doutrina cristã se refere. O documento "Epístola da Tradução", dentro do III Concílio Limense, constitui um marco legal que cria normas para controlar a qualidade ideológica e linguística das traduções, e propõe que para fazê-las: "Se haga juntas de lenguas de personas doctas y religiosas para que de conformidad se haga la traducción de este mismo Catecismo." Assim como "está ordenado que se use solamente de las traducciones aprovadas por este Concilio provincial".*

A tarefa de uniformização proposta pelo III Concílio Limense tenta controlar não só a diversificação pastoral, mas, sobretudo, implica uma intervenção no planejamento da língua. A política homogeneizante - uma língua, uma versão - exige tomar decisões frente a esse conjunto de diversidades.

Para este fim, são elaboradas propostas que seguem os lineamentos do modelo peninsular de "ordenamento" no âmbito das línguas, especialmente na implementação e escolha de uma língua geral regional. Entretanto, se abre um grande debate sobre a possibilidade de línguas indígenas serem capazes de comportar o ideário cristão. Essa questão gera polêmicas acaloradas dentro das ordens religiosas, que chegam até aos níveis deliberativos mais altos
(SOLANO, Francisco. Documentos sobre Política Lingüística en Hispanoamérica - 1492-1800. Madrid: Consejo Superior de Investigaciones Científicas, 1991: 85.)

* (SOLANO, Francisco. op. cit.: 85-86.) 
•(TORERO, Alfredo. "Entre Roma y Lima; el Lexicon Quichua de Fray Domingo de Santo Tomás [1560]". In: ZIMMERMANN, Klauss (ed.) La descripción de las lenguas amerindias en la época colonial. Madrid: Vervuert-Iberoamericana, 1997: 283.) da Igreja - os Concílios - em que, após argumentações e contraargumentações, são submetidas à votação.

Nesse quadro, um dos lados do conflito vê a língua castelhana como a língua civilizadora e, em contrapartida, vê nas línguas indígenas o reduto das idolatrias. A tese contrária, que acabará sendo a dominante, defende o uso das línguas indígenas, chamadas gerais, pelas funções de comunicação interétnica, para desempenhar um novo papel na difusão da doutrina cristã.

Para ilustrar as controvérsias levantadas em relação à terminologia cristã, é representativo o caso da discussão em torno da tradução do item lexical Dios. A propósito de um Catecismo em uma língua indígena de Guatemala, publicado pelos franciscanos no México, os dominicanos promovem uma polêmica que envolve questôes teológicas e linguísticas. Uma parte da ordem criticara o catecismo franciscano por traduzir o termo Dios do espanhol, en el nombre que significaba Dios en la lengua [indígena] com o seguinte argumento: como los indios no formaban concepto de lo que significaba esta palabra "Dios", andaban desatinados porque no podian concebir a Dios em [língua] romance. No entanto, o próprio superior dominicano, após uma visita, proibirá o nome "Cabahuil", termo indígena escolhido para a tradução, ordenando a sua substituição pelo nome de Dios, o "verdadeiro", nas açôes de catequese na região. Este episódio mostra não só as contradições no seio da própria instituição, mas a relação que se estabelece entre retórica e ideologia, na representação das línguas.

No mundo andino, as divindades, as práticas religiosas e os ritos nas línguas indígenas constituem objeto de grande perseguição por serem considerados veículos de idolatrias. A preocupação e cuidados especiais podem ser observados na composição dos léxicos e vocabulários. Frei Domingo de Santo Tomás compóe o Lexicón o Vocabulário de la Lengua General del Peru (1560), seguindo as entradas do Vocabulário Hispano-latino de Nebrija (1495). A tarefa encomendada é a de construir um universo de conceitos cristãos adequando o léxico quéchua. Y

alli donde las hubiese o por perífrasis y remantizaciones [...] 'desconstruir', paralizar, la tradición andina en todo aquello que contrariase la imposición del Evangelio y del dominio hispano, silenciando el léxico quechua de contenido religioso indígena cuando no pudiese ser remantizado...*

A questão de fundo é que o uso das línguas indígenas na tarefa de catequese implica a decisão de traduzir nelas a doutrina cris- 
tã materializada na produção de Catecismos nas diferentes línguas gerais, assim como se estava fazendo a tradução do latim às línguas vulgares europeias, com objetivos de difusão religiosa. Essa determinação representa todo um investimento que envolve, entre outras, propostas ortográficas para as línguas sem escrita assim como a elaboração de Artes ou Gramáticas e Dicionários.

Domingo de Santo Tomás observa que deve omitir: "cosas que no tenian ni se usauan en aquellas tierras [...] muchos términos de frutas, de aves, animales, officios, vestidos [...] delas cosas de la fe católica, de ornamento de iglesias....”* Termos enraizados nas tradiçôes religiosas andinas são também omitidos, por ser objeto de erradicação, como parte da política de extirpação de idolatrias.

A identificação das idolatrias com a língua consta da "lista" de práticas condenadas no II Concílio. Uma das estratégias delineadas é a convocação de experts em línguas indígenas para elaborar instrumentos catequéticos nas línguas gerais, visando à difusão da doutrina cristã, segundo a orientação do Concílio de Trento (1545-1563).

Os Vocabulários estão constituídos por dicionários bilíngues, espanhol-línguas indígenas, que têm por objetivo viabilizar a tradução de itens lexicais de uma língua a outra e vice-versa, reproduzindo o formato dos primeiros dicionários de línguas vulgares, LatimRomance, como uma tentativa de estabelecer correspondências de natureza semântica entre ambas as línguas. Isto para cumprir com uma das principais tarefas da organização do trabalho de catequese, que consiste na produção de materiais nas duas línguas gerais mais importantes da área andina: quéchua e aymara.

Os problemas descritivos que se colocam numa Gramática por se tratar de línguas tipologicamente tão diferentes são escamoteados no Vocabulário, em que os itens lexicais são apresentados isoladamente, como uma lista de palavras plausíveis de apresentarem equivalências. Itens como no caso das etnocategorias representam um desafio à tradução, cuja solução geralmente é pelo viés do etnocentrismo. Assim, seguindo o modelo de Nebrija, o Vocabulário quéchua de Frei Domingo de Santo Tomás [1560] desdobra entradas lexicais para dar conta do contato. Na parte Espanhol-Quéchua, para o termo "sacerdote", por exemplo, formula duas entradas: i) sacerdote de ydolos traduzida pelo termo quéchua: "homo" e ii) sacerdote de christiano: "runa diospa cococ", adaptando uma formulação quéchua a partir do cognato dios. Já na parte Quéchua-Espanhol do Léxico, o termo homo, que corresponde a "sacerdote", é
"(SANTO TOMÁS, Fray Domingo. Lexicon o Vocabulario de la lengua general del Perú. [1560] Madrid: Agencia de Cooperación Española, 1994: Prologo al lector.) 
(TORERO, Alfredo. op. cit: 282.)

'(SANTO TOMÁS, Fray Domingo. op. cit. loc. cit.)

(SOLANO, Francisco. op. cit.: 99.)

- (TAYLOR, Gerald. Ritos e Tradiciones de Huarochiri del siglo XVII. Lima: Instituto de Estudios Peruanos \& Instituto Francés de Estudios Andinos, 1987.) traduzido como agorero, hechizero, passando, assim, por ressemantizações e diferenciações explicativas entre as concepções cristãs e as das religiōes andinas, indicadoras já da presença da Inquisição. Da mesma forma, o termo quéchua de divindade: guaca é correspondido pelo termo espanhol ydolo.

A tradução de discursos eclesiásticos, guardando os princípios próprios dessa retórica nas línguas indígenas, é considerada uma tarefa difícil. A Gramática [da língua quechua] de frei Domingo de Santo Tomás inclui uma tradução da Plática para todos los Indios, com a avaliação que a tradução se hizo con no pequeño trabajo, por la mucha difficultad que ay en declarar cosas tan difficiles y desusadas a los Indios. *

Essa avaliação é compartilhada pelo jesuíta José de Acosta, que após fazer um paralelo entre as lenguas indicas, o hebreu, o grego e o latim, para provar a sua simplicidade e facilidade em aprendê-las, e ainda dizer que, apesar dos sons bárbaros, são capazes de modos de decir tan bellos y elegantes, afirma que essas línguas tienen una gran penuria de palabras, porque como bárbaros [los índios] carecian del conocimiento de estos conceptos.

Se bem que as tarefas de codificação, elaboração de gramáticas e propostas ortográficas sejam vistas como de natureza técnica, no terreno da codificação léxica as implicações sociais e culturais ganham outra dimensão. No caso do universo andino, esses dicionários desempenham um papel "intervencionista”, porque levam a uma reformatação da Língua Geral quéchua. Neste processo silencioso e pouco visível que Torero chama de ressemantização, a cosmogonia e religiões andinas são minadas pela reconceitualização de termos tradicionais e ao mesmo tempo, de introdução de termos novos a partir da criação de novos significantes em quéchua para categorias cristãs.

\section{A Inquisição e as línguas}

O episódio histórico conhecido como de "Extirpação de Idolatrias", um dos mais devastadores para as culturas indígenas, representa um momento-chave para a guinada, histórica e linguística, da força desestruturadora, no que se refere à coesão cosmogônica do mundo andino. Ao final do século XVI, sob o comando do Santo Oficio, é produzido um manuscrito, como parte do trabalho conhecido como Ritos e Tradiçôes de Huarochiri. ${ }^{*}$ Trata-se de uma espécie de Relatório, em que informantes narram mitos e descrevem práticas religiosas andinas. Escrito em língua geral quéchua, o ma- 
nuscrito é uma peça dos autos inquisitoriais e, portanto, apresenta também uma versão em espanhol.

A estratégia ideológica inquisitorial representa as religiōes andinas como uma doença idolátrica, da qual esse documento constitui uma prova, por conter termos heréticos em língua indígena. Em contrapartida, é estabelecida uma "cura” em De procuranda indorum salute, do jesuíta e intelectual José Acosta, que encaminha a campanha de repressão idolátrica como um remédio para combater a enfermidade.

Esta campanha tem na língua um dos meios de acesso e diagnóstico, observável nos interrogatórios e na documentação recolhida, mas também na construção dos "medicamentos" como um dos instrumentos de reformatação ou construção de um mundo andino cristão. Dessa forma, as medidas políticas e o planejamento de línguas estão motivados principalmente pela erradicação dessas práticas heréticas, inerentes às línguas indígenas.

Anjo bom ou anjo mau?

A ressemantização de alguns itens lexicais ao longo do período colonial e a sua dicionarização até o presente constitui uma pista para entender essa política intervencionista, no que se refere à cosmogonia e ideologia religiosa.

No Lexicón de La Lengua General del Perú (1560), Fray Domingo de Santo Tomás consigna como traduçôes do termo çupay: "ángel bueno o malo"; "demonio, bueno o malo" representando uma entidade neutra do sistema religioso andino. Já no manuscrito de Huarochiri (1579?) o termo aparece, tanto em quéchua quanto na versão bilíngue, como mana alli supay: "neg. bom espírito", alternando com supay para designar demônio, portanto oscilando entre espírito e demônio.

Originalmente Supay foi traduzido por "sombra" ou "alma dos antepassados”, já no final do século XVI, a campanha da Inquisição cristaliza o significado do cristianíssimo "diabo" para essa entidade andina. Como resultado desse processo, nos dicionários contemporâneos Quéchua-Espanhol, ${ }^{4}$ nas seis variantes da língua quéchua, constam os seguintes registros para a entrada léxica supay:

\footnotetext{
${ }^{4}$ Série de Dicionários editados pelo Instituto de Estudios Peruanos e o Ministério de Educación, com apoio do Depto de Linguística da Universidad de San Marcos. Obras de referência na lexicografia quéchua. CERRÓN-PALOMINO, Rodolfo Diccionario Quechua Junin-Huanca. ME/IEP: Lima, 1976; CUSIHUAMÁN, Antonio Diccionário Quechua Cuzco-Collao. ME/IEP: Lima, 1976; PA-
} 
Lexicón o Vocabulario de la Lengua General del Perú (1560) çupay "ángel bueno o malo"

\begin{tabular}{|l|l|}
\hline \multicolumn{1}{|c|}{ DicionÁrios -1976 } & \multicolumn{1}{c|}{ SUPAY } \\
\hline $\begin{array}{l}\text { Diccionario Quechua } \\
\text { Ayacucho-Chanca. }\end{array}$ & s. diablo, espiritu maligno \\
\hline $\begin{array}{l}\text { Diccionário Quechua } \\
\text { Cuzco-Collao }\end{array}$ & $\begin{array}{l}\text { s. diablo, demonio. Supay wasi: } \\
\text { 'Infierno'. Supaypa wawan: } \\
\text { 'bijo del diablo'. }\end{array}$ \\
\hline $\begin{array}{l}\text { Diccionario Quechua } \\
\text { Ancash-Huaylas }\end{array}$ & $\begin{array}{l}\text { s. 'Demonio'. Cf. hupay, shapi, } \\
\text { shapinku, shapsa. }\end{array}$ \\
\hline $\begin{array}{l}\text { Diccionario Quechua } \\
\text { Junin-Huanca }\end{array}$ & $\begin{array}{l}\text { s. 'Diablo' // Usase también } \\
\text { como insulto. }\end{array}$ \\
\hline $\begin{array}{l}\text { Diccionario Quechua de } \\
\text { San Martín }\end{array}$ & $\begin{array}{l}\text { s. 'Diablo'. Supayuk adj. } \\
\text { 'Endemoniado' }\end{array}$ \\
\hline $\begin{array}{l}\text { Diccionario Quechua } \\
\text { Cajamarca-Cañaris }\end{array}$ & $\begin{array}{l}\text {--------- } \\
\text { esp. Demonio: Shapinku. } \\
\text { Awqa* manalli }\end{array}$ \\
\hline
\end{tabular}

"Awqa: s. 'demonio, enemigo; gato, judiol adj. Tonto, opa, ignorante, tonto

Pode-se observar como a "divindade" andina foi ressemantizada negativamente, de forma que a sua invocação implicou castigos de toda natureza, perseguição, tortura e execração pública. Desta maneira, a entrada léxica cristalizou um significado até o ponto, como se pode observar em um dos dicionários, de marcar uma das funçôes do termo, a de insulto.

Em contrapartida, para a entrada léxica do espanhol Dios na correspondência quéchua os mesmos dicionários oferecem a tradução a seguir:

RK, M. WEBER, N.; CENEPO, V. Diccionario Quechua de San Martín. ME/ IEP: Lima, 1976; PARKER, Gary; CHÁVEZ, Amancio Diccionario Quechua Ancash-Huaylas. ME/IEP: Lima, 1976; SOTO RUIZ, Clodoaldo. Diccionario Quechua Ayacucho-Chanca. ME/IEP: Lima, 1976.; QUESADA, Félix. Diccionario Quechua Cajamarca-Cañaris. ME/IEP: Lima, 1976. 


\begin{tabular}{|l|l|}
\hline \multicolumn{1}{|c|}{ DicionÁRIO-I976 } & \multicolumn{1}{c|}{ Dios } \\
\hline $\begin{array}{l}\text { Diccionario Quechua } \\
\text { Ayacucho-Chanca }\end{array}$ & --------------- \\
\hline $\begin{array}{l}\text { Diccionário Quechua } \\
\text { Cuzco-Collao }\end{array}$ & Dyus o Yus; Yaya \\
\hline $\begin{array}{l}\text { Diccionario Quechua } \\
\text { Ancash-Huaylas }\end{array}$ & Dyos, kamakoq \\
\hline $\begin{array}{l}\text { Diccionario Quechua } \\
\text { Junin-Huanca }\end{array}$ & ------------- \\
\hline $\begin{array}{l}\text { Diccionario Quechua } \\
\text { de San Martín }\end{array}$ & Dyus \\
\hline $\begin{array}{l}\text { Diccionario Quechua } \\
\text { Cajamarca-Cañaris }\end{array}$ & Amitu, tayta, siñur, yaya \\
\hline
\end{tabular}

As equivalências para o quéchua são formadas a partir dos empréstimos do léxico espanhol Dios, que ocorre na maioria das variantes quéchua. Aparecem outras formas castelhanas como "amitu" (amo. dim.), "tayta" (pai em espanhol antigo), "siñur", ou as formas quéchua kamacoc (o fazedor), yaya (pai), compatíveis com o ideário cristão. Em dois dicionários (Junin e Ayacucho) não consta a entrada.

Esses dados evidenciam o apagamento dos nomes étnicos que fazem parte dos sistemas nas religiōes andinas tradicionais, como resultado da política tradutória intervencionista das instâncias de poder, no caso, a Igreja. Apesar dos setores "indianistas" serem vitoriosos no uso das línguas gerais indígenas na catequese, a ideologia que representa essas línguas como incapazes de comportar o sagrado, monopolizado pelo ideário cristão, acabam predominando:

...los vocabularios servían de instructores y de códigos morales [...] Eran uma base para transformar el idioma de los autóctonos y, mediante esto, el pensamiento y la cosmovisión, una meta muy clara de la evangelización.

O dicionário representa, assim, uma autoridade que funciona como uma das instituições sociais na produção e difusão de representaçōes, no caso do dicionário bilíngue, as escolhas na tradução acabam sedimentando a reprodução dessa visão dominante.

" (Thiemer-Sachse, Ursula. "El Vocabulario castellanozapoteco de Juan de Córdoba". In: Zimmermann, Klauss (ed.) La descripción de las lenguas amerindias en la época colonial. Madrid: Vervuert-lberoamericana, 1997:152.) 
Dicionários:

CERRÓN-PALOMINO, Rodolfo. Diccionario Quechua JuninHuanca. ME/IEP: Lima, 1976.

CUSIHUAMÁN, Antonio. Diccionario Quechua Cuzco- Collao. ME/IEP: Lima, 1976.

PARK, M. WEBER, N. \& CENEPO, V. Diccionario Quechua de San Martín. ME/IEP: Lima, 1976.

PARKER, Gary \& CHÁVEZ, Amancio. Diccionario Quechua Ancash-Huaylas. ME/IEP: Lima, 1976.

NEBRIJA, Antonio de. Vocabulario español-latino [1495]. Ed. facsimilar de Madrid: Real Academia Española, 1951.

SANTO TOMÁS, Fray Domingo Grammatica: o Arte de la lengua general de los indios de los reynos del Perú. [1560] Centro de estudios regionles Bartolomé de las Casas: Cuzco, 1995.

SANTO TOMÁS, Fray Domingo. Lexicon o Vocabulario de la lengua general del Perú. [1560]. Agencia de Cooperación Española: Madrid, 1994.

SOTO RUIZ, Clodoaldo. Diccionario Quechua Ayacucho-Chanca. ME/IEP: Lima, 1976.

QUESADA, Félix. Diccionario Quechua Cajamarca-Cañaris. ME/ IEP: Lima, 1976. 


\section{Consuelo Alfaro Lagorio}

Doutora em Educação Bilíngue pela Pontifícia Universidade Católica do Peru (1972), com Pós-Doutorado pela Université de Paris VII - Université Denis Diderot, França (1983). Professora Associada da Universidade Federal do Rio de Janeiro, atuando no Programa de Pós-Graduação em Letras Neolatinas - Estudos Linguísticos nos seguintes temas: linguística hispânica, ensino de língua estrangeira, ensino e aprendizagem. Integra o GT da ANPOLL: Historiografia Linguística Brasileira.

\section{Resumo}

As decisões políticas da administração colonial na América hispânica em relação às línguas têm a ver diretamente com a catequese. Após a escolha das línguas a serem usadas para este fim, no caso as línguas gerais assim chamadas pelas funções de comunicação interétnicas, começa um debate dentro das ordens missioneiras sobre a capacidade de essas línguas comportarem a doutrina cristã. Para levar adiante a ação evangelizadora, investe-se na produção de Gramáticas, Dicionários bilíngues e propostas ortográficas para essas línguas que viabilizam a produção de catecismos. A questão debatida neste artigo está centrada nas políticas de tradução explicitadas pelos Concílios, que implicam, entre outros, a ressemantização dos termos étnicos que designam as entidades e as práticas das religiōes andinas, num processo de satanização que pode ser observado nos Dicionários, na tradução à língua espanhola das entradas léxicas e, ao mesmo tempo, na incorporação de empréstimos do castelhano às línguas indígenas.

\section{Abstract}

The language policy carried out by the colonial administration of hispanic America is directly linked to the catechism of the Catholic Church. When the decision of which languages to use for catechism was taken (in this case the general languages) a debate arose among the missionary orders about whether or not these languages were able

\section{Resumen}

Las decisiones políticas de la administración colonial en América hispánica en el campo de las lenguas tienen que ver directamente con la catequesis. Después de optar por las lenguas que serán usadas para este fín, en el caso las lenguas generales, así llamadas por las funciones de comunicación interétnicas, comienza un debate
Palavras-chave: tradução historiografia linguística; lexicografia; línguas indígenas; política linguística.
Key words: translation; translation, linguistic historiography, lexicography, indian languages, linguistic politics

Palabras clave: traducción; historiografia lingüística; lexicografía; lenguas indígenas; política lingüística. 
to transmit the Christian doctrine. The evangelization process brought about the production of grammar books, bilingual dictionaries and spelling suggestions for these languages.

This article focuses on the translation policies defined by the Church Councils. These included the resemanticization of ethnic terms defining the Entities and andean religious practices. The Spanish translation of lexical entries in dictionaries of that period, as well as the adoption of certain Spanish words into indigenous languages, reveal the nature of the demonizing process that was carried out. dentro de las órdenes misioneras sobre la capacidad de estas lenguas en comportar la doctrina cristiana.

Para llevar a cabo la acción evangelizadora se invierte en la producción de Gramáticas, Dicionarios bilingües y propuestas ortográficas para estas lenguas que viabilicen la producción de catecismos. La cuestión debatida em este artículo está centrada en las políticas de traducción explicitadas en los Concilios que implica, entre otros, la ressemantização de los términos étnicos que designan las entidades y las prácticas de las religiones andinas, en un proceso de satanización que se puede observar en los Diccionarios, en la traducción a la lengua española de las entradas léxicas y al mismo tiempo, en la incorporación de empréstimos del castellano a las lenguas indígenas. 